\title{
E-LOGISTICS - ASPECTS OF FUNCTIONING
}

\author{
Ryszard Barcik, Marcin Jakubiec
}

\section{Key words:}

e-business, e-logistics, B2B, B2C, C2C, data base, EDI, RFID, eSCM

\begin{abstract}
In the background of changing situation on local and global markets of delivery and sales companies more often use the Internet tools, letting realization of electronic transactions with partners in supply chain. Changes in management of supply chain happen with development of clients' needs and technological possibilities of cooperating partners. Globalization of economic companies' cooperation (e.g. in delivery, production and distribution processes), technological growth and innovative manners of economic activity, as well as stronger competition and shorter products life cycles on markets have caused pressure on changes of dimensions of supply chains' acts - shorter time of order's realization, global scope of activity, bigger elasticity and durability. One of fundamental tool of supporting business processes became electronic data interchange through the Internet. It has caused epochmaking change for clients' values — independent access to information about products' flow and localization of supply chain's partners.
\end{abstract}

\section{FUNDAMENTS OF E-LOGISTICS}

In the background of changing situation on local and global markets of delivery and sales companies more often use the Internet tools, letting realization of electronic transactions with partners in supply chain. Changes in management of supply chain happen with development of clients' needs and technological possibilities of cooperating partners. Globalization of economic companies' cooperation (e.g. in delivery, production and distribution processes), technological growth and innovative manners of economic activity, as well as stronger competition and shorter products life cycles on markets have caused pressure on changes of dimensions of supply chains' acts - shorter time of order's realization, global scope of activity, bigger elasticity and durability. One of the fundamental tools of supporting business processes have became electronic data interchange through the Internet. It has caused an epoch-making change for clients' values — an independent access to information about products' flow and localization of supply chain's partners [6].

The growth of share of electronic commerce in commerce in general (all over the world and in Poland) has caused a need of an online access to logistic services amid suppliers and recipients on market. Growth of electronic commerce evaluating towards e-business has brought about a natural need of the growth of processes of the commodity flow service, in the area of the company front-office (e.g. sales, marketing, client service), as well as back-office (purchasing, warehousing, transport, production and co-production). The electronic data interchange between partners let them cooperate in real time and create an integrated supply chain. Efficient, reliable and effective functioning of supply chains requires beyond good management of physical products flow, set under functional and organizational aspect, a system of information flow (flow and computerization) [6]. 
Experiences achieved up to the present in the area of e-business enable to distinguish the following business models which define relations of market's partners [1]:

1. a business to business model (B2B) - this model embraces main economic contacts, it means their preparation, assessment of partners' risk, negotiating and realization of order until full payment.

2. a business to customer model (B2C) - it concerns financial services (e.g. electronic banking, insurances, investment funds), non-financial services (e.g. touristic services) and trade centers (the Internet shops).

3. a customer to customer model (C2C) - this model mainly includes hobby contacts or attendance in auctions.

Evaluating towards virtual organization a company could achieve bigger effectiveness, extend its sources base and join new markets all over the world. Main advantages of e-business are [1]:

- lower costs of functioning,

- efficient management of the supply chain,

- shorter time cycles and quicker reaching the market by product,

- new possibilities of promotion,

- improvement of client services,

- extended productivity of employees.

Among barriers of e-business use are [1]:

- data safety,

- durability and capacity of connections,

- communication standards,

- access to historical data.

Partners in global chains and delivery nets use many present solutions of e-logistics to service business activity. Electronic services of logistic processes run by companies in the supply chain require the use of many electronic tools accessible through the Internet. It has brought about functional separation in the framework of e-economy in many areas of electronic services available through the Internet, e.g. e-purchasing, e-production, e-commerce, elogistics, e-marketing, etc [6].

However, many trials have been done e-logistics term does not have one agreed definition. It is concerned that e-logistics means the use of systems, informatics tools and the Internet as communication medium to service logistic processes[6].

The most often used tools of cooperation in the virtual scope of e-logistics are (fig. 1)[6]:

- the Internet portal,

- electronic platform,

- electronic catalogue,

- data warehouses,

- information services,

- systems of offers and purchasing,

- transactions systems,

- systems and communication tools,

- systems and software, e.g. applications of supply chains' planning, dictionaries, digital maps, e-learning systems, etc. 
In the article examples of e-logistics tools would be described.

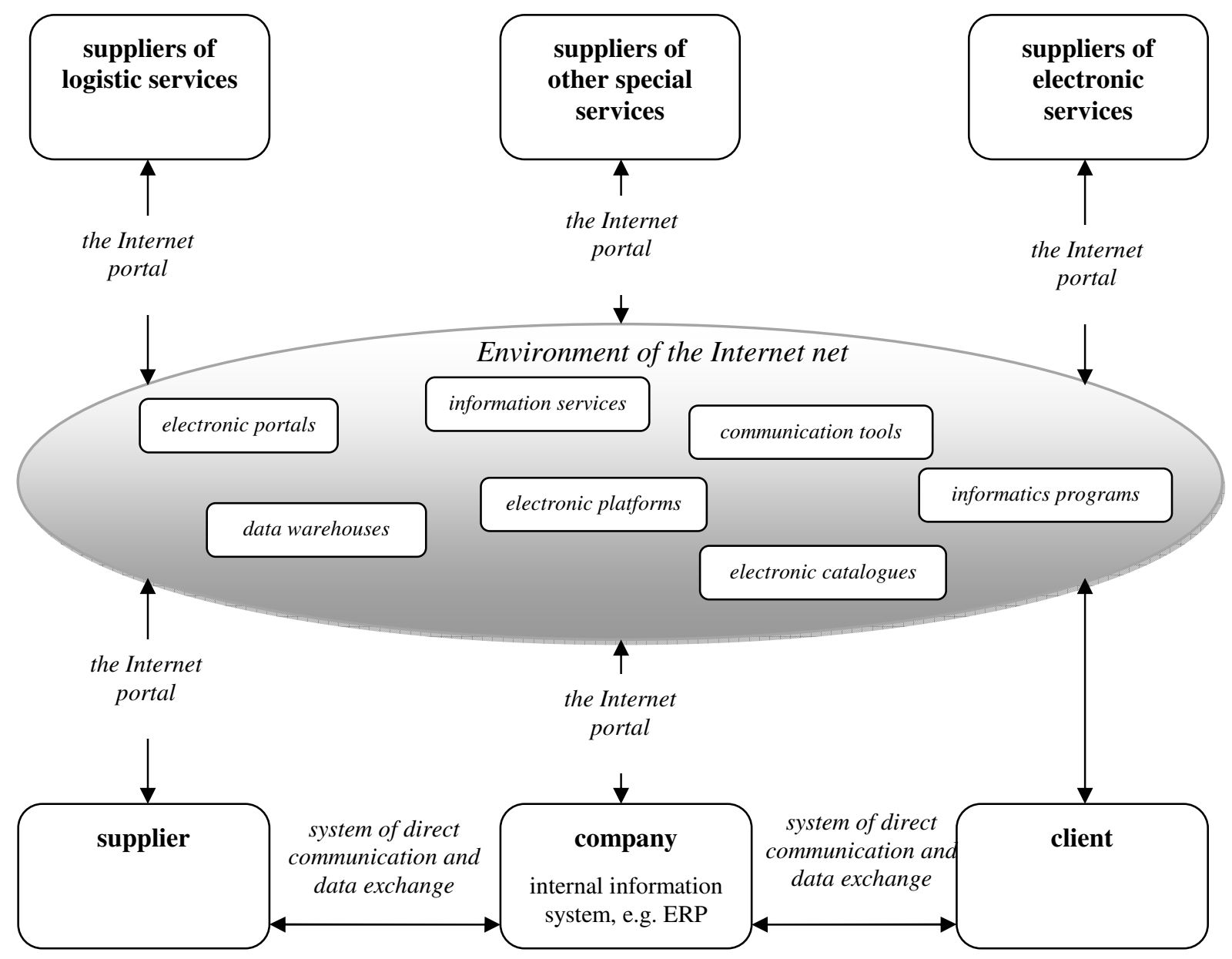

Fig. 1. Example of e-logistics environment Source: Personal elaboration based on [6]

\section{DATA BASE}

In the modern world, it could not be visualized a well functioning company without the use of the data base. Neither technical nor organizational means could not ensure such a quick and elastic access to reliable information as well projected system of the data base. For an obvious reason data bases are the most important component of all platforms supporting business processes, especially supporting supply chain management. They constitute a core of advanced logistic systems, e.g. ERP. The data bases also are a fundament of functioning and information exchange between business partners across the supply chains called SCM systems and building so called data warehouses collecting information coming from different links of those chains. In general, a data base is defined as an ordered collection of data holding in computer memory. The system of the data base stands for the data with program means letting simultaneous operating on it and simultaneous searching and updating of included in it information [4].

Reasoning and effective acting on a data base is related with the proper interpretation of collected in it data, which requires a real and full description of semantics of the real world 
modeling. In a data base a tool to description of the real world semantics reflected by a data base is a data model. The data model stands for a collection of abstractive terms letting representation of properties of this world. The terms collection used for the description of the real world part properties, important from the point of view of the exact usage creates a schedule of the data base. An important term, often confused with the data base term, is the system of data base management. It is described as a collection of programs enabling creating and exploitation of the data base. These are programs (software) of overall usage making easier defining processes, constructing and computerizing the data base for different applications [4].

A data base is characterized by four fundamental features[4]:

- independence of applications and data,

- abstractive representation of data,

- different ways of data perceiving,

- physical and logical independence of data.

\section{ELECTRONIC DATA INTERCHANGE}

EDI (Electronic Data Interchange) is a non-paper technique of exchange of formalized data (documents) between informatics systems of trade partners with minimum intervention of human being. The data which are an object of electronic exchange are counterparts of the content of traditional trade documents: orders, invoices, production drafts, etc. An advantage of EDI is independence from the hardware platform and operating system and the software platform (from user application). EDI is based on international standards. Data transmission in EDI is done by electronic links between computers, not by exchangeable data carriers. EDI technique is a definitive manner of using of transmission nets (fig. 2) [5].

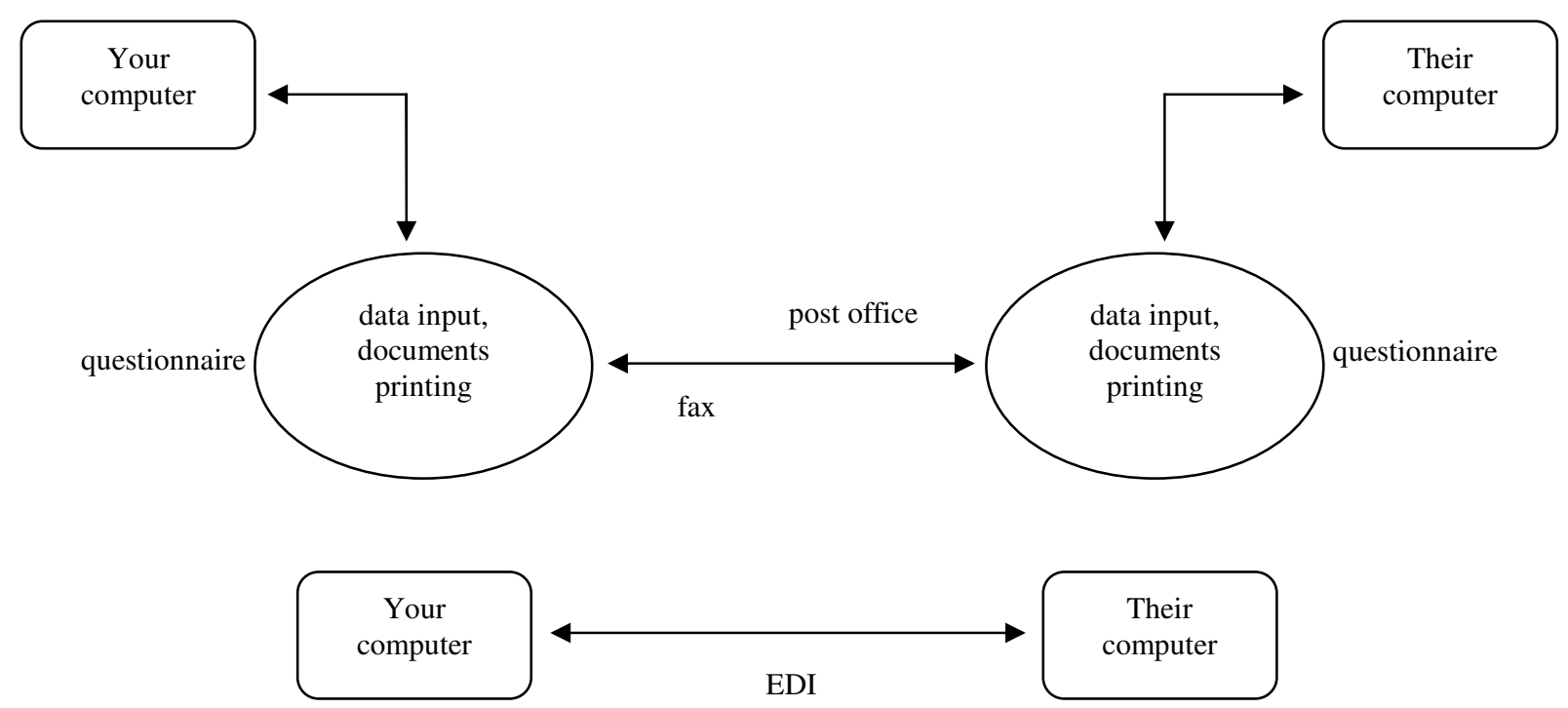

Fig. 2. Electronic data interchange versus traditional methods Source: Personal elaboration based on [5] 
EDI software realizes the following functions (fig. 3) [5]:

- export and import of data from/to application - enables cooperation with company's usable applications, e.g. Excel,

- data conversion - output documents are turn into EDI communicates; input ones

- translate on proper format for usable applications,

- sending and receiving EDI communicates - service of communication net in scope of connections, setting of transmission's parameters and data sending,

- management and control of documents' turnover — these are additional functions which scope is determined by software and could embrace: documents' archives, a data base of EDI partners, data coding and their compression, connecting and disconnecting operations, etc.

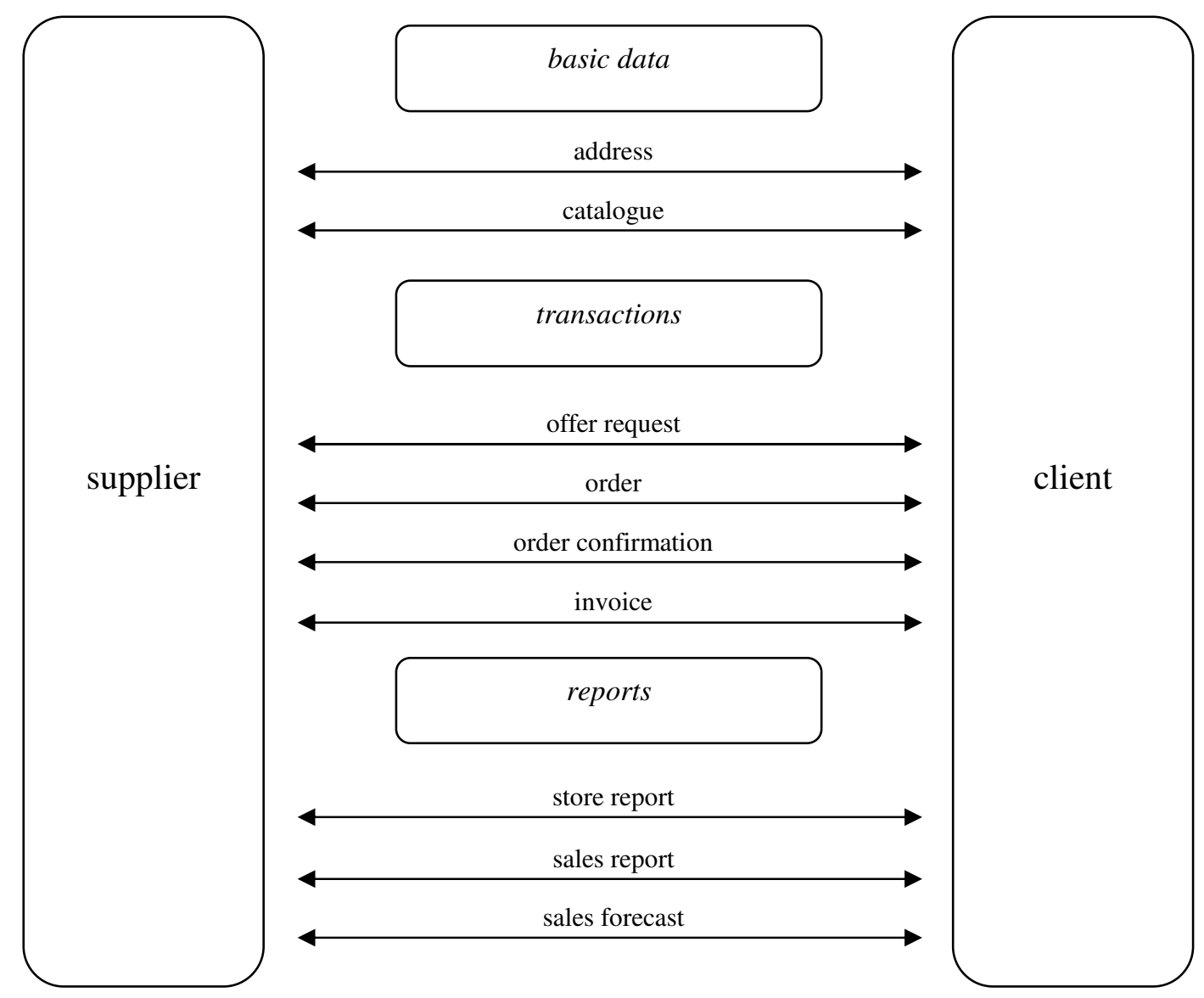

Fig. 3. Examples of exchange of EDI communicates between trade partners Source: Personal elaboration based on [5]

\section{IDENTIFICATION TECHNOLOGY — RADIO FREQUENCY IDENTIFICATION (RFID)}

A new technology of identification called "radio bar code", from one side steers thinking on change of the medium from bar code on radio waves, from the other side new possibilities of product's describing on label put on every package could be easily noticed. In this new technology not radio technique is so important, but a way of data saving in memory of the microprocessor, called a chip. A radio wave of proper frequency stimulates a chip antenna, what implicates radio data transmission from the chip memory to a reader and then to a 
computer. RFID term could be a little bit confusing because not a radio wave is a medium of information, but a memory put in a small chip (in terms of parameters, not in terms of capacity). E.g. chip capacity $0,5 \mathrm{kB}$ is 512 bits to free use. The free use of bits' potential will not give much if it is not standardized. Similarly to bar code technology, from many symbols in the global use five were chosen, so in example of bits' potential some of their scope was chosen with the beginning address and length of 96 bits to a common use by all who want to act in global supply nets. In the example of the chip capacity $0,5 \mathrm{kB}$, minus 96 bits reserved for the global use, minus 16 bits reserved for the individual number of the chip given by its producer stays 400 bits for the individual use. Those 96 bits is Electronic Product Code (EPC) identifying with "radio bar code" should have been called "bar code of next generation". EPC code is a big challenge for Fast Moving Customer Goods branch because it exploits RFID technology in which identifying number is saved in the special tag put on a product and to its read radio wave about proper frequency is used [7].

RFID technology is not a new one, but its connection with the Internet brought about big potential hidden in it - creation of EPC concept. EPC implementation enables quicker and easier identification of transportation packages' content and possibility of goods' flow tracking in real time, also over integrated supply chains on global level of supply nets. EPC solution brings much more possibilities of its use than the bar code because it constitutes a connection of RFID with global link means through the Internet, often called "products' Internet". EPC was designed within the pattern of used bar codes GS1, where object's identification is separated from information, which causes that system is elastic. During changing of identifying object's feature or its use, the identifier will always stay unchangeable. Information about products will be placed in dispersed data available in the Internet. Implementation of EPC does not require any change of functioning numeration in GS1 system [7].

\section{INFORMATION INTEGRATED SYSTEMS}

Beginnings of information integrated systems go back to the 50s of the twentieth century. Their goal was to manage inventory using known methods (IC - inventory control). Those systems involved only one area of company's activity, so it was difficult to call them integrated. At the beginning of the $60 \mathrm{~s}$ a breakthrough in creating of systems for management support was noticed. Its direct consequence was implementation of MRP system (material requirements planning). MRP systems were perceived as a tool to calculate and control the store - they did not give any possibilities of system's monitoring and did not leave a place for feedback. Lack of monitoring was causing that systems were not sensitive to differences between a plan and reality and to unpredicted accidents. MRP systems had to be extended. They got additional functions to collect and respect information from suppliers and salesmen. The static MRP model got needed dynamics. Further evolution brought about MRP II systems (manufacturing resources planning), which became more complex tools relating gradually to much more areas of company's activity. MRP II systems meet the following functions: sales and operation planning, demand management, master production scheduling, material requirement planning, a bill of material subsystem, an inventory transaction system, a scheduled receipt subsystem, shop floor control, capacity requirement planning, input/output control, purchasing, distribution resource planning, tooling planning and control, financial planning interface, simulations and performance measurement [2]. 
Another type of information integrated system is ERP (enterprise resource planning), which was created in the 90s of the twentieth century as the effect of MRP II evolution. ERP systems support company management in the area of planning, production and distribution and enables a quick response on demand change in terms of conditions and restrictions on the market. ERP is also often defined as a packet of software for enterprise resource planning, which is ready for implementation of integrated groups of modules, servicing all business functions of company and enabling dynamic possibility of configuration. A main purpose of a packet is full integration of all areas of company. It should support specialized production functions, e.g. management of construction and technological changes, as well as quality management, redecorations, services, staff, etc. Amidst many tasks of ERP systems their characteristic element is generating of multidimensional financial analysis for top management. ERP systems serve setting of information for the needs of users and simulation of activities, their analysis and effects [2].

\section{E-SUPPLY CHAIN MANAGEMENT}

Spreading out of e-business and the Internet brought about that integration of the supply chain in the technological area happens more often through the Internet. That integration got a new name eSCM (electronic Supply Chain Management). Thanks to eSCM it is possible to create dynamic reconfigured supply chains, so called temporary supply chains, which are built for the needs of even simple transactions of individual clients. Such configuration is often something more than an ordinary supply chain, making up a net of connected suppliers and partners. eSCM systems configure with the following parts: eCommerce, eProduction, eLogistics, ePlanning, eDelivery and eDesigning. From many advantages of the use of the Internet technology in SCM a few could be mentioned: lowering of order realization costs, possibility of the use of just in time concept, a lower store in warehouses, restriction of documents' amount, making shorter of procedures, automatics, fewer mistakes, bigger loyalty of clients, shorter time of orders' realization, coordination of orders with suppliers and recipients, restriction of agents' amount and stronger links with trade partners. A further step in evolution of SCM systems would be full net integration. This is the most advanced SCM model under theoretical consideration. Its characteristic feature is unknown electronic optimization of orders and reduction of rotation time, achieving thanks to full communicative integration of all business partners [4].

\section{SUMMARY}

Dynamically growing possibilities of interactive partners' cooperation, electronic data interchange and an access to global information sources have brought about a visible change of company's business model. Possibilities of dynamic planning and control ( $24 \mathrm{~h} / 7$ days per week) caused another phase of interest in outsourcing. Many companies have moved their core business from production to deliveries management from subcontractors, electronically targeting order realization and client service. Global supply chain, possibilities of their configuration and options of cooperation have caused an interest in logistic services' integration in the supply chain, realized by a logistic operator (4th Party Logistics). An increasingly common access to electronic data nets and logistic services, electronic data interchange, as well as electronic integration of planning and organizing of supply chains, also coordination and management of subcontractors' activities create fundaments of another stage of outsourcing development, described as 5th Party Logistics. Electronic access to many data geared managers' interest towards niche markets, letting precise management of size and term 
of delivery to remote places, as well as areas of high competitive products' satisfaction or low level of customer service[6].

A more often appreciated source of logistic strategy's success is concentration on client's needs satisfaction. Purposes of the strategy are clear[6]:

- ensure clients' access to good quality products,

- ensure products' access when clients need them,

- achieve a level and structure of costs letting compete of prices,

- ensure a trustworthy and reliable image of company.

It is possible, although it was difficult to connect the strategy of products' differentiation and individualize client service with the strategy of high capacity of the supply chain, mass market service, high efficiency of acting and visible for clients a low level of prices.

\section{Literature:}

[1] ADAMCZEWSKI, P. Informatyczne wspomaganie tańcucha logistycznego. Wyd. Akademii Ekonomicznej w Poznaniu, Poznań, 2001.

[2] CIESIELSKI, M. [red.] Instrumenty zarzqdzania logistycznego. PWE, Warszawa, 2006.

[3] CIESIELSKI, M. [red.] Instrumenty zarzadzania łańcuchami dostaw. PWE, Warszawa, 2009.

[4] DŁUGOSZ, J. [red.] Nowoczesne technologie w logistyce. PWE, Warszawa, 2009.

[5] GOŁEMBSKA, E. [red.] Kompendium wiedzy o logistyce. wydanie IV zmienione, Wyd. Naukowe PWN, Warszawa, 2010.

[6] KISPERSKA-MOROŃ, D., KRZYŻANIAK, S. [red.] Logistyka. Wyd. Biblioteka Logistyka, Poznań, 2009.

[7] MAJEWSKI, J. Informatyka dla logistyki. Wyd. Biblioteka Logistyka, Poznań, 2008.

\section{JEL M15, M20}

prof. ATH dr. hab. Ryszard Barcik, mgr Marcin Jakubiec

University of Bielsko-Biała

Faculty of Management and Information Sciences

Department of Management

Ul. Willowa 2

43-309 Bielsko-Biała, Poland

m.jakubiec@ath.eu 